\title{
Labour Analgesia
}

\author{
Rabindran ${ }^{1}$, Gedam DS ${ }^{2}$ \\ ${ }^{1}$ Dr. Rabindran, Consultant, Neonatologist, Billroth Hospital, Chennai, India, ${ }^{2}$ Dr D Sharad Gedam, Professor of \\ Paediatrics, L. N. Medical College, Bhopal, MP, India.
}

Address for Correspondence: Dr Rabindran, E mail: rabindranindia@ yahoo.co.in

\begin{abstract}
Regional anaesthesia is nowadays commonly practised universally. It provides superior pain relief in first \& second stages of labour, anesthesia for episiotomy \& instrumental delivery.
\end{abstract}

Keywords: Labour Analgesia, Regional anaesthesia, Labour pain

\section{Introduction}

International Association for Study of Pain declared 2007-2008 as 'Global Year against Pain in Women Real Women, Real Pain' [1]. Labour pain is of main concern \& labour analgesia is of utmost importance. Uterine contraction \& cervical dilatation result in visceral pain whereas fetal head descent \& pressure on pelvic floor, vagina $\&$ perineum generates somatic pain. Methods of labour analgesia include 1) Nonpharmacological methods like Transcutaneous electrical nerve stimulation, continuous support in labour, touch \& massage, water bath, intradermal sterile water injections, acupuncture, acupressure, aromatherapy \& hypnosis [2]; 2) Parenteral narcotics like Pethidine, Intravenous ketamine, Fentanyl- for patient-controlled intravenous analgesia (PCA), Tramadol, Butorphanol \& Remifentanil; 3) Inhalation methods like nitrous oxide, sevoflurane-for PCA isoflurane \& enflurane [3]; 4) Regional analgesiaepidural, combined spinal/epidural (CSE- needlethrough-needle/ coaxial technique) \& spinal, Central neuraxial analgesia, sequential needle-through-needle combined spinal epidural technique (CSEA), Patientcontrolled epidural analgesia (PCEA), Programmed intermittent epidural boluses (PIEB) \& Computerintegrated PCEA (CI-PCEA) where background infusion rates vary depending on previous hour's demand boluses [4]. CSEA is restricted for very early stage of labour where local anaesthetics are avoided, advanced stages of labour where rapid analgesia is desirable \& difficult epidurals as CSEA reduces failure rate of epidurals; 5) Local anaesthetic nerve blocks like pudendal \& paracervical block.
Regional anaesthesia is nowadays commonly practised universally. It provides superior pain relief in first \& second stages of labour, anesthesia for episiotomy \& instrumental delivery, extension of anesthesia for cesarean delivery \& avoidance of opioid-induced maternal \& neonatal respiratory depression from intravenous opioids, facilitates atraumatic vaginal delivery of twins, preterm neonates, neonates with breech presentation \& controls blood pressure in women with preeclampsia by alleviating labor pain. Combined spinal/epidural method has advantages like rapid \& effective analgesia, continued ambulation during labor, low incidence of hypotension \& combination of benefits of spinal \& epidural blocks. Spinal (subarachnoid, intrathecal) block is short-lasting useful for short procedures like forceps/ vacuum delivery. Low dose epidural infusion decreases instrumental vaginal delivery by $25 \%$ \& small-bore atraumatic spinal needles reduce incidence of postdural puncture headache.

Indications for regional anaesthesia include Maternal request, marked obesity, placenta previa, high order multiple gestation, severe preeclampsia, bleeding disorders, use of anticoagulants, severe edema, trauma, surgery, anatomical abnormalities of face, neck/ spine, abnormal dentition, small mandible, extremely short stature, short neck, arthritis, goiter, cardiovascular, neurological or respiratory disease. Contraindications for Regional anesthesia include maternal hemorrhage, refractory hypotension, coagulopathy, untreated bacteremia, raised intracranial pressure, skin/ soft tissue 
infection at epidural site, aortic stenosis, pulmonary hypertension \& right-to-left shunts. Low-dose epidural regimes \& PCEA has reduced total dose \& side-effects like motor blockade [5].

Labour analgesia has some side effects. PethidineNeonatal adversity [6]; Ketamine- airway compromise \& neonatal respiratory depression; Butorphanolrespiratory depression; Remifentanil- maternal hypoventilation; Nirous oxide- environmental pollution; Sevofluorine- environmental pollution, maternal amnesia \& loss of protective airway reflexes; CSEApruritus, vomiting, hypotension, uterine hyperstimulation, foetal bradycardia \& maternal respiratory depression; CSE with microcatheters- cauda equina syndrome; Inadvertent intravascular lidocainetinnitus, circumoral numbness, metallic taste, dizziness $\&$ tachycardia.

Newer local anaesthetics like ropivacaine \& levobupivacaine have increased maternal safety. $\alpha-2$ agonist, clonidine, cholinesterase inhibitor \& neostigmine are useful adjuvants [7]. Ultrasound guided neuraxial technique is useful for obese women $\&$ those with scoliosis [8]. Novel loss of resistance methods facilitate epidural space detection like air operated Epidrum \& spring-loaded AutoDetect syringe Episure [9]. Novel epidural needles like Needle-shaped Ultrasound probe are recent advances [10] .

\section{Funding: Nil, Conflict of interest: None.} Permission of IRB: Yes

\section{References}

1. Sunil T Pandya.Labour analgesia: Recent advances. Indian J Anaesth. 2010 Sep-Oct; 54(5): 400-408. Doi: 10.4103/0019-5049.71033.

2. Simkin PP, O'hara M. Nonpharmacologic relief of pain during labor: Systemic reviews of five methods. Am J Obstet Gynecol. 2002;186:5;S131-59.

3. Yeo ST, Holdcroft A, Yentis SM, Stewart A, Bassett P. Analgesia with sevoflurane in labour. II. Sevoflurane compared with entonox for labour analgesia. $\mathrm{Br} \mathrm{J}$ Anaesth. 2007 Jan ;98:110-5.
4. Ban Leong Sng, David Woo, Wan Ling Leong, Hao Wang, Pryseley Nkouibert Assam, Alex TH Sia. Comparison of computer-integrated patient-controlled epidural analgesia with no initial basal infusion versus moderate basal infusion for labor and delivery: A randomized controlled trial. J Anaesthesiol Clin Pharmacol. 2014 Oct-Dec; 30(4): 496-501.doi: 10. 4103/0970-9185.142842.

5. Boulier V, Gomis P, Lautner C, Visseaux H, Palot M, Malinovsky JM. Minimal concentration of ropivacaine and levobupivacaine with sufentanil for epidural analgesia in labour. Internal J Obstet Anaesth. 2009; 18:226-30.

6. Sosa CG, Balaguer E, Alonso JG, Panizza R, Laborde A, Berrondo C. Meperidine for dystocia during the first of labor: A randomized controlled trial. Am J Obstet Gynecol. 2004 Oct;191(4):1212-8.

7. Wallet F, Clement HJ, Bouret C, Lopez F, Broisin F, Pignal C, et al. Effects of a continuous low-dose clonidine epidural regimen on pain, satisfaction and adverse events during labour: a randomized, doubleblind, placebo-controlled trial. Eur J Anaesthesiol. 2010 Mar; 27 (5):441-7. DOI: 10.1097/ EJA.0b 013e32833 65944.

8. Arzola C, Davies S, Rofaeel A, Carvalho JC. Ultrasound using the transverse approach to the lumbar spine provides reliable landmarks for labour epidurals. Anesth Analg. 2007 May;104(5):1188-92.

9. Kim SW, Kim YM, Kim SH, Chung MH, Choi YR, Choi EM. Comparison of loss of resistance technique between Epidrum ${ }^{\circledR}$ and conventional method for identifying the epidural space. Korean J Anesthesiol 2012 Apr; 62 (4): 322-6.doi: 10.4097/ kjae.2012.62.4. 322.

10. Desjardins AE, Hendriks BH, van der Voort M, Nachabé R, Bierhoff W, Braun G, et al. Epidural needle with embedded optical fibers for spectroscopic differentiation of tissue: Ex vivo feasibility study. Biomed Opt Express 2011 Jun 1; 2(6): 1452-1461.doi: 10.1364/BOE.2.001452.

\section{How to cite this article?}

Rabindran, Gedam DS. Labour Analgesia. Int J Med Res Rev 2017;5(01):01-02.doi:10.17511/ijmrr. 2017.i01.14 